\title{
Antitumor effects of curcumin in human bladder cancer in vitro
}

\author{
JING SHI, XU ZHANG, TAOPING SHI and HONGZHAO LI \\ Department of Urology, Chinese People's Liberation Army General Hospital, Beijing 100853, P.R. China \\ Received September 11, 2015; Accepted February 13, 2017
}

DOI: $10.3892 / \mathrm{ol} .2017 .6205$

\begin{abstract}
Bladder cancer is one of the major causes of cancer-associated mortality, with a high incidence. Curcumin, a polyphenol compound extracted from turmeric, has been identified to regulate tumor progression. However, the therapeutic effect of curcumin in human bladder cancer has not yet been determined. In the present study, the effects of curcumin on cell growth, apoptosis and migration of bladder cancer cell lines were evaluated using an MTT assay, a Transwell assay and flow cytometry, and the associated mechanisms were investigated using western blot analysis. Curcumin was identified to decrease the growth of T24 and 5637 cells in a dose- and time-dependent manner. The present study confirmed that curcumin is able to inhibit cell migration and promote apoptosis of bladder cancer through suppression of matrix metalloproteinase signaling pathways in vitro. The anticancer effects of curcumin on bladder cancer cells may benefit clinical practice in the future.
\end{abstract}

\section{Introduction}

Bladder cancer is one of the major causes of cancer-associated mortality, with a high incidence (1). The majority of patients with bladder cancer initially present with non-muscle-invasive disease; however, disease recurrence is observed in between 30 and $56 \%$ of patients undergoing surgery (2). Radical cystectomy with urinary diversion is currently the standard treatment for those patients with refractory non-muscle-invasive and muscle-invasive bladder cancer (3). Although there has been recent progress in the development of treatments, the prognosis for patients with advanced bladder cancer following cystectomy is poor $(4,5)$. Therefore, identification of effective molecular therapeutic targets to treat advanced bladder cancer is urgently required.

Curcumin is a dietary antioxidant derived from turmeric, which may possess anti-inflammatory, anti-proliferative and

Correspondence to: Professor Xu Zhang, Department of Urology, Chinese People's Liberation Army General Hospital, 28 Fuxing Road, Haidian, Beijing 100853, P.R. China

E-mail: drzhangx6@163.com

Key words: bladder cancer, curcumin, migration, matrix metalloproteinase, apoptosis pro-apoptotic properties (6,7). Curcumin induces the activation of pro-apoptotic and anti-tumorigenic signaling pathways (8). However, the therapeutic potential of curcumin against various cancer cells, its effects, and the molecular pathways involved in suppression of bladder cancer growth and metastasis remain unclear. In the present study, the anticancer effects of curcumin on bladder cancer in vitro were examined. It was investigated whether curcumin induces bladder cancer cell apoptosis and inhibits bladder cancer cell survival and invasion.

\section{Materials and methods}

Reagents and cell culture. Curcumin (Sigma-Aldrich; Merck KGaA, Darmstadt, Germany) was prepared by dissolving it in dimethylsulfoxide (DMSO) at a stock concentration of $5,000 \mathrm{mM}$ and stored at $-20^{\circ} \mathrm{C}$. Serial dilutions were prepared in culture medium. Human urinary bladder transitional cell carcinoma (T24 and 5637) cells were obtained from the Chinese Academy of Science (Shanghai, China). T24 and 5637 cell lines were maintained in RPMI-1640 medium (Gibco; Thermo Fisher Scientific, Waltham, MA, USA) supplemented with $10 \%$ fetal bovine serum (FBS; Biological Industries, Cromwell, CT, USA). All media contained 100 units $/ \mathrm{ml}$ penicillin and $100 \mu \mathrm{g} / \mathrm{ml}$ streptomycin. All cell lines were maintained at $37^{\circ} \mathrm{C}$ in a humidified incubator containing $5 \% \mathrm{CO}_{2}$. The cells that entered the exponential growth period were selected for experiments.

Proliferation assay (MTT assay). T24 and 5637 cells in the exponential growth phase were inoculated on 96-well plates at a density of $4 \times 10^{3} /$ well, and sterile PBS was added to the edge well as a control. After $24 \mathrm{~h}$ at $37^{\circ} \mathrm{C}$, curcumin was added at the concentrations of 5, 10, 20, 30 and $40 \mu \mathrm{mol} / 1$. The experimental control group ( $0.1 \%$ DMSO) and zero group were set up, and each group contained 3 wells. Following treatment, $10 \mu \mathrm{l} \mathrm{MTT} \mathrm{solution} \mathrm{was} \mathrm{added} \mathrm{to} \mathrm{each} \mathrm{well} \mathrm{for} 2 \mathrm{~h}$ at $37^{\circ} \mathrm{C}$, prior to dissolving the formazan product using DMSO, and cell viability was determined by measuring the absorbance at $540 \mathrm{~nm}$ using a microplate spectrophotometer (Molecular Devices, LCC, Sunnyvale, CA, USA). The mean percentage of viable cells \pm standard deviation generated from three independent experiments are reported.

Determination of cell apoptosis by flow cytometry. Following treatment, apoptosis was detected using the Annexin V-fluorescein isothiocyanate (FITC) Apoptosis Detection kit (BD Biosciences, Franklin Lakes, NJ, USA). T24 and 5637 cells 
A

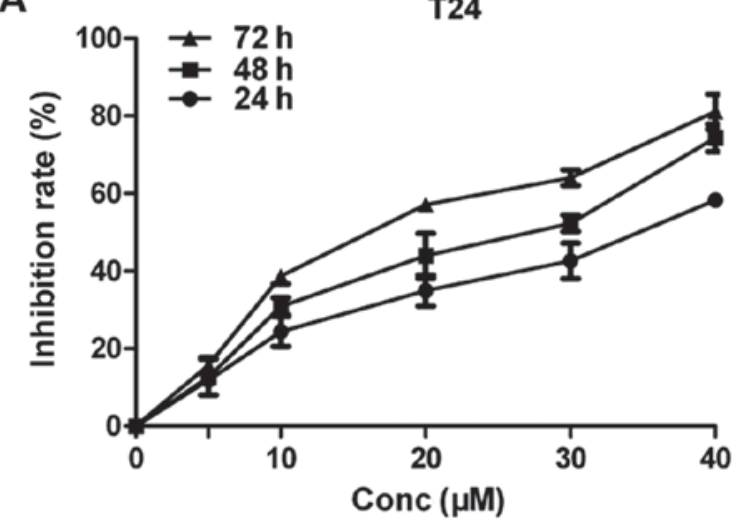

B

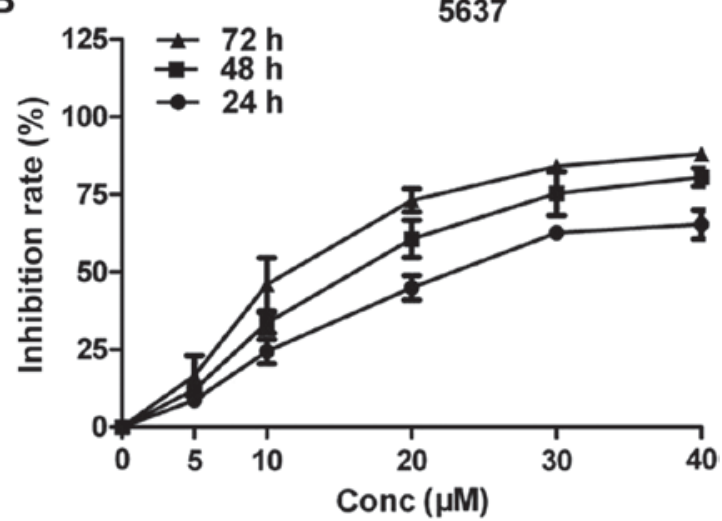

Figure 1. Inhibitory effect of curcumin on T24 and 5637 cells after 24, 48 and 72 h, measured using an MTT assay. (A) The survival rate of T24 cells with various concentrations of curcumin. (B) The survival rate of 5637 cells with various concentrations of curcumin. Conc, concentration.

were detached by trypsinization and washed three times in PBS, centrifuged at $1,000 \mathrm{xg}$ for $5 \mathrm{~min}$ at $4^{\circ} \mathrm{C}$ and resuspended in $195 \mu$ l Annexin V-FITC binding buffer. A $5 \mu$ l volume of Annexin V-FITC was added and mixed. The cells were then stained with Annexin V-FITC binding buffer in the dark for $10 \mathrm{~min}$ at room temperature. Subsequently, cells were centrifuged at $1,000 \mathrm{x} \mathrm{g}$ for $5 \mathrm{~min}$ at $4^{\circ} \mathrm{C}$ and resuspended in $190 \mu \mathrm{l}$ Annexin V-FITC binding buffer. Finally, $10 \mu \mathrm{l}$ propidium iodide (PI) staining solution was added and mixed. The cells were kept on ice for $30 \mathrm{~min}$ in the dark and immediately subjected to flow cytometry analysis. The data were analyzed using Cell Quest BD FACStation $^{\text {TM }}$ v6.0x (BD Biosciences, Franklin Lakes, NJ, USA). The experiment was repeated three times.

Caspase 3/7 enzyme activity assay. Caspase 3/7 enzyme activity was determined using the Caspase-Glo 3/7 assay (Promega Corporation, Madison, WI, USA), according to the manufacturer's protocol. Cells $\left(10^{4}\right.$ cells/well) were plated in a 96-well plate in $100 \mu \mathrm{l}$ culture medium in the absence or presence of 5 , 10 and $20 \mu \mathrm{mol} / 1$ curcumin. Caspase-Glo 3/7 reagent (100 $\mu \mathrm{l})$ was added to each well and the plates were incubated at room temperature for an additional $1 \mathrm{~h}$. Finally, the luminescence of each sample was measured by a luminometer (Beckman Coulter, Inc., Brea, CA, USA; DTX 880 Multimode Reader).

Cell migration assay. Transwell inserts with a pore size of $8 \mathrm{~mm}$ from Corning Incorporated (Corning, NY, USA) were used to determine tumor cell migration capacity. Following culture for $24 \mathrm{~h}$ at $37^{\circ} \mathrm{C}$, T24 and 5637 cells were starved in medium without FBS for $24 \mathrm{~h}$, and $5 \times 10^{4}$ cells were then resuspended in the FBS-free medium and placed in the upper chambers in triplicate. The cells remaining on the upper membrane were removed with cotton wool, whereas the cells that had migrated to the bottom of the membrane were fixed with $95 \%$ ethanol and stained with $0.1 \%$ crystal violet. Five visual fields of each insert were randomly selected and images were captured under a light microscope at x200 magnification. All experiments were performed in triplicate.

Western blot analysis. Cells were inoculated into the culture flask at $1 \times 10^{4}$ cells $/ \mathrm{cm}^{2}$. Following adherence, cells were treated with $10 \mu \mathrm{mol} / 1$ curcumin or $0.1 \%$ DMSO (negative control group). Following incubation for $24 \mathrm{~h}$ at $37^{\circ} \mathrm{C}$, cells were lysed using the mammalian protein extraction reagent, radioimmunoprecipitation buffer (Beyotime Institute of Biotechnology, Haimen, China), supplemented with a protease inhibitor cocktail (Roche Diagnostics, Basel, Switzerland) and PMSF (Roche Diagnostics). Protein $(30 \mu \mathrm{g})$ were separated by SDS-PAGE (10\% gels), transferred to a polyvinylidene difluoride membranes (EMD Millipore, Billerica, MA, USA). and blocked with 5\% skimmed milk at room temperature for $1 \mathrm{~h}$. Cells were washed with TBS-Tween-20 (TBST) three times for $5 \mathrm{~min}$. The primary antibodies against matrix metalloproteinase (MMP)-2 (rabbit mAb; cat no., 87809; dilution, 1:1,000; Cell Signaling Technology, Inc., Danvers, MA, USA), MMP-9 (rabbit mAb; cat. no., 13667; dilution, 1:1,000; Cell Signaling Technology, Inc.) and tissue inhibitor of metalloproteinase-2 (TIMP-2; rabbit mAb; cat. no., 5738; dilution, 1:1,000; Cell Signaling Technology, Inc.) were added to the membrane prior to incubation at $4^{\circ} \mathrm{C}$ overnight. The membrane was washed with TBST three times for $5 \mathrm{~min}$. The secondary antibody (1:10,000; anti-rabbit $\mathrm{IgG}$, horseradish peroxidase-linked antibody; cat. no., 7074; Cell Signaling Technology, Inc.) was added to the membrane and agitated for $1 \mathrm{~h}$ at room temperature prior to washing three times with TBST for $5 \mathrm{~min}$. The blot was imaged using an enhanced chemiluminescent imaging system (Pierce; Thermo Fisher Scientific, Inc.).

Statistical analysis. All values are presented as the mean + standard error of the mean. For the MTT assay, the results are presented as the mean \pm standard deviation. Statistical significance was determined using Student's t-test. $\mathrm{P}<0.05$ was considered to indicate a statistically significant difference.

\section{Results}

Curcumin inhibits the proliferation of bladder cancer cells. To determine the inhibitory effect of curcumin on bladder cancer cells, an MTT assay was performed. The concentration of curcumin used was 5, 10, 20, 30 and $40 \mu \mathrm{mol} / 1$. When the concentration of curcumin was $>10 \mu \mathrm{mol} / 1$, the action time was $>24 \mathrm{~h}$, the growth of cells was inhibited in a time- and dose-dependent manner and the difference was statistically significant $(\mathrm{P}<0.001$; Fig. 1A and $\mathrm{B})$. These results indicated 
A

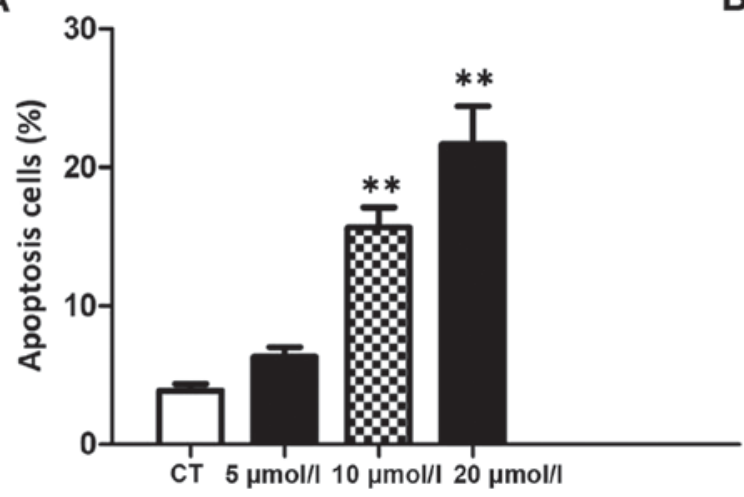

B

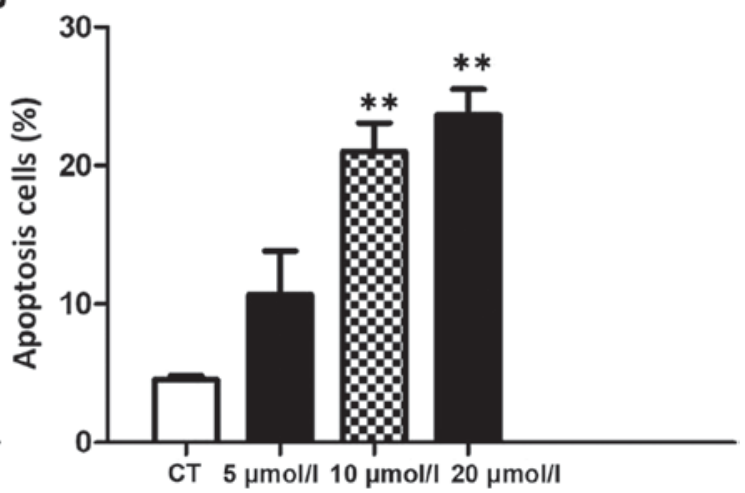

Figure 2. (A) Apoptosis in T24 cells treated with various concentrations of curcumin after $24 \mathrm{~h}$. (B) Apoptosis in 5637 cells treated with various concentrations of curcumin after $24 \mathrm{~h}$. ${ }^{* *} \mathrm{P}<0.01$ vs. control.

A

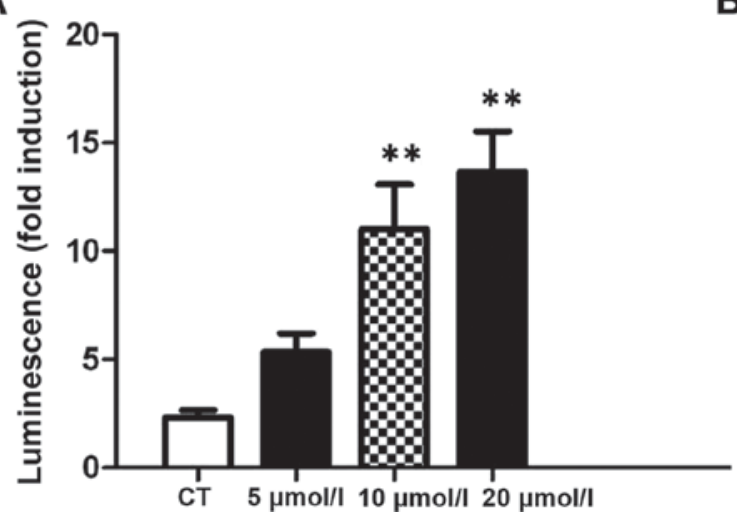

B

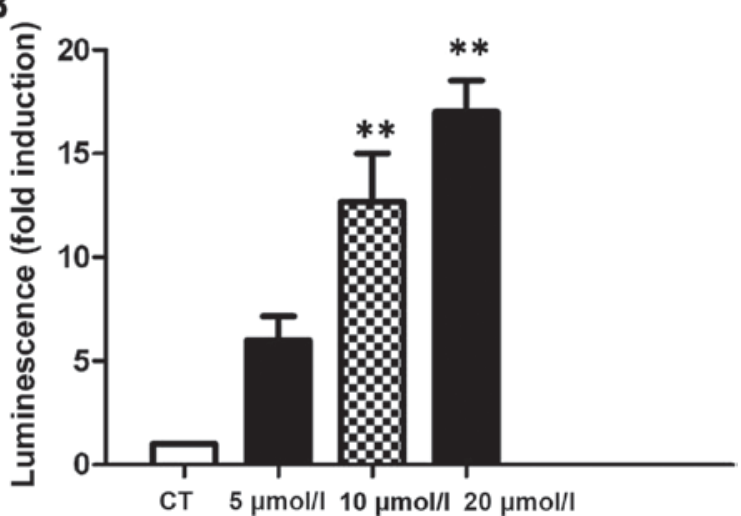

Figure 3. (A) Increasing concentrations of curcumin-stimulated caspase activity in T24 cells. (B) Increasing concentrations of curcumin stimulated caspase activity in 5637 cells. ${ }^{* *} \mathrm{P}<0.01$ vs. control.

that curcumin exhibited a strong inhibitory effect on the survival rates of T24 and 5637 cells. In the subsequent tests, 5,10 and $20 \mu \mathrm{mol} / 1$ curcumin were selected to investigate the effects of curcumin on bladder cancer cells and explore the underlying molecular mechanisms.

Effect of curcumin on apoptosis of bladder cancer cells. To determine whether curcumin induces apoptosis of T24 and 5637 cells, Annexin V FITC/PI staining was performed. Annexin V and PI staining results indicated that, with an increase in curcumin concentration after $24 \mathrm{~h}$, the number of apoptotic cells was also markedly increased $(\mathrm{P}<0.01$; Fig. 2A and B). These results indicated that curcumin induces increased apoptosis in T24 and 5637 cells.

Caspase 3/7 enzyme activity in response to curcumin in bladder cancer cells. In order to evaluate whether caspases serve roles in curcumin-induced apoptosis of bladder cancer cells, the levels of caspase 3/7 were measured following treatment with various concentrations of curcumin for $24 \mathrm{~h}$. The results revealed that there was a dose-dependent increase in caspase 3/7 enzyme activity in curcumin in T24 and 5637 cells (Fig. 3A and B). These results demonstrated that there was a dose-dependent increase in caspase 3/7 enzyme activation in curcumin-treated T24 and 5637 cells which induced significantly increased apoptosis compared with the control.
Effect of curcumin on the migratory ability of bladder cancer cells. The Transwell invasion chamber experiments demonstrated that the number of T24 and 5637 cells passing through the polycarbonate membrane in the high concentration group was significantly less compared with that in the control group and the low concentration group $(\mathrm{P}<0.01$; Fig. 4A and $\mathrm{B})$. Compared with the negative control group, the number of transmembrane cells gradually decreased as the drug concentration of curcumin increased, and the differences between each group were statistically significant $(\mathrm{P}<0.01)$.

Effect of curcumin on expression of MMP-2, MMP-9 and TIMP-2 in T24 cells. The expression of MMP-2, MMP-9 and TIMP-2 was examined using western blotting in T24 cells (Fig. 5). The results indicated that the expression of MMP-2 and MMP-9 proteins was significantly decreased $(\mathrm{P}<0.01)$, and that of the TIMP-2 protein was significantly increased, in the $10 \mu \mathrm{M}$ curcumin group compared with the control group. These results confirmed that curcumin inhibits cell metastatic potential via MMP pathways.

\section{Discussion}

Bladder cancer is one of the most frequent urological malignancies, which is characterized by increasing incidence and mortality (9). It has been proposed that chemotherapy represents 
A

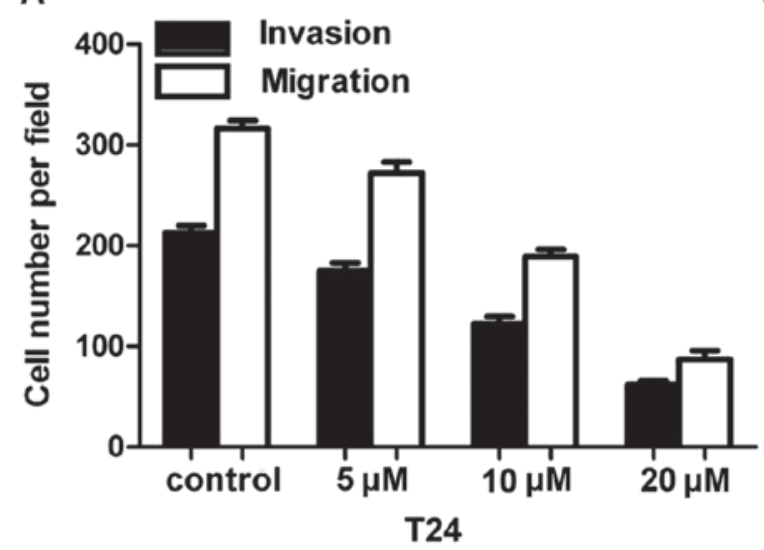

B

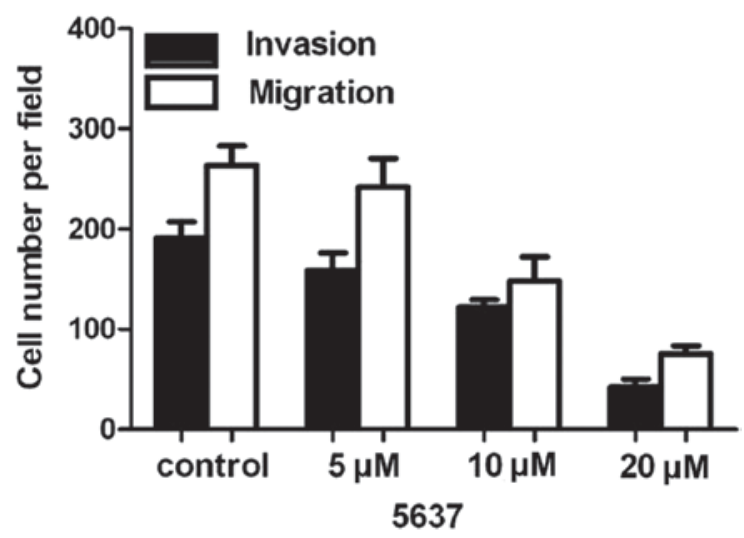

Figure 4. Migration and invasion of (A) T24 and (B) 5637 cells treated with various concentrations of curcumin after 24 h.

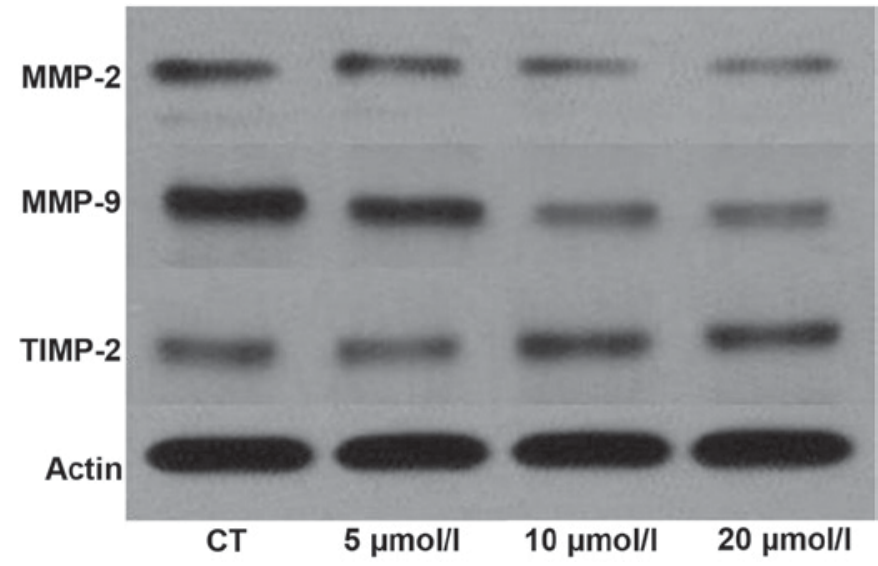

Figure 5. Western blot analysis of the expression of proteins after T24 cells were treated with curcumin. The levels of MMP-2, MMP-9 and TIMP-2 were analyzed by western blot analysis. $\beta$-actin was used as a loading control. MMP, matrix metalloproteinase; TIMP-2, tissue inhibitor of metalloproteinase-2; CT, control.

important modality for patients with bladder cancer (10). However, the prognosis of bladder cancer remains poor (11). Early diagnosis and effective treatment are essential in order to increase the life expectancy of patients with bladder cancer.

Curcumin is a polyphenol compound extracted from turmeric that has been identified to regulate tumor progression $(12,13)$. Previous studies have focused on curcumin due to its anticancer properties $(14,15)$. However, there have been few studies on the effect of curcumin on the survival and invasion of bladder cancer cells. In the present study, the underlying molecular mechanism of curcumin in bladder cancer was investigated by studying the effect of curcumin on proliferation and apoptosis of the human bladder cancer cell lines T24 and 5637.

Several effects of curcumin have been identified. One of them is the effect of curcumin on coronary heart disease $(15,16)$. In addition, curcumin has been safely demonstrated to function as an antitumor drug $(17,18)$. The efficacy of curcumin on the proliferation of bladder cancer in vitro was examined, and the results demonstrated that curcumin inhibits cell proliferation in a time- and dose-dependent manner. The results indicated that curcumin is a potential anticancer drug for the treatment of bladder cancer. The results of the present study identified that curcumin may cause significant growth inhibition in bladder cancer cell lines, which was in accordance with the aforementioned previous studies $(19,20)$.

Curcumin exhibited the ability to effectively modulate the apoptotic effect of cancer cells $(20,21)$. The results of the present study identified that the number of apoptotic cells increased markedly with an increase in curcumin concentration, indicating that curcumin induces apoptosis in two human urinary bladder transitional cell carcinoma cells. In addition, caspase $3 / 7$ activity was examined, and the results indicated that curcumin stimulated a marked increase in caspase activity beginning at concentrations of 10 and $20 \mu \mathrm{mol} / \mathrm{l}$.

A previous study has demonstrated that curcumin may inhibit the metastasis of melanoma cells in vitro (22). The results of the present study are in agreement with previous studies $(23,24)$; curcumin inhibited the migration of T24 and 5637 cells. To date, few studies have investigated the molecular mechanisms through which curcumin inhibits metastasis (25). Curcumin may impede cell metastasis via downregulation of Src and focal adhesion kinase activity, two important factors in integrin signal transduction (26). In the present study, curcumin inhibited the migration of bladder cancer cells by inhibiting MMP signaling pathways. MMPs belong to a family of $\mathrm{Zn}^{2+}$-dependent endogenous proteolytic enzymes. MMPs degrade almost all components of the extracellular matrix, with the exception of polysaccharides, and are involved in invasion and metastasis of tumors. The results of western blot analysis indicated that the expression of MMP-2 and MMP-9 proteins was significantly decreased in the $10 \mu \mathrm{M}$ curcumin group compared with the control group, which confirmed that curcumin inhibits cell metastatic potential via MMP signaling pathways.

In conclusion, the results of the present study identified that the anticancer effects of curcumin inhibited cell proliferation and migration, and promoted apoptosis of bladder cancer cell through the suppression of MMP signaling pathways. Additional studies are required to determine the in vivo anticancer effects of curcumin in animal models, in order to evaluate the therapeutic potential of curcumin on bladder cancer cells and the potential benefits of curcumin for clinical practice in the future. 


\section{References}

1. Siegel R, Ma J, Zou Z and Jemal A: Cancer statistics, 2014. CA Cancer J Clin 2014 64: 9-29, 2014.

2. von der Maase H, Sengelov L, Roberts JT, Ricci S, Dogliotti L, Oliver T, Moore MJ, Zimmermann A and Arning M: Long-term survival results of a randomized trial comparing gemcitabine plus cisplatin, with methotrexate, vinblastine, doxorubicin, plus cisplatin in patients with bladder cancer. J Clin Oncol 23: 4602-4608, 2005.

3. Shirodkar SP and Lokeshwar VB: Potential new urinary markers in the early detection of bladder cancer. Curr Opin Urol 19: 488-493, 2009.

4. Kim WJ and Bae SC: Molecular biomarkers in urothelial bladder cancer. Cancer Sci 99: 646-652, 2008.

5. Witjes JA, Compérat E, Cowan NC, De Santis M, Gakis G, Lebret T, Ribal MJ, Van der Heijden AG and Sherif A; European Association of Urology: EAU guidelines on muscle-invasive and metastatic bladder cancer: Summary of the 2013 guidelines. Eur Urol 65: 778-792, 2014.

6. Okudan N, Belviranlı M, Gökbel H, Oz M and Kumak A: Protective effects of curcumin supplementation on intestinal ischemia reperfusion injury. Phytomedicine 20: 844-848, 2013.

7. Fan Z, Jing H, Yao J, Li Y, Hu X, Shao H, Shen G, Pan J, Luo F and Tian X: The protective effects of curcumin on experimenta acute liver lesion induced by intestinal ischemia-reperfusion through inhibiting the pathway of NF- $\kappa \mathrm{B}$ in a rat model. Oxid Med Cell Longev 2014: 191624, 2014.

8. Anand P, Sundaram C, Jhurani S, Kunnumakkara AB and Aggarwal BB: Curcumin and cancer: An 'old-age' disease with an 'age-old' solution. Cancer Lett 267: 133-164, 2008.

9. Kirkali Z, Chan T, Manoharan M, Algaba F, Busch C, Cheng L, Kiemeney L, Kriegmair M, Montironi R, Murphy WM, et al: Bladder cancer: Epidemiology, staging and grading, and diagnosis. Urology 66 (6 Suppl 1): S4-S34, 2005.

10. Nargund VH, Tanabalan CK and Kabir MN: Management of non-muscle-invasive (superficial) bladder cancer. Semin Oncol 39: 559-572, 2012.

11. Chaffer CL, Brennan JP, Slavin JL, Blick T, Thompson EW and Williams ED: Mesenchymal-to-epithelial transition facilitates bladder cancer metastasis: Role of fibroblast growth factor receptor-2. Cancer Res 66: 11271-11278, 2006.

12. Jain SK, Gill MS, Pawar HS and Suresh S: Novel curcumin diclofenac conjugate enhanced curcumin bioavailability and efficacy in streptococcal cell wall-induced arthritis. Indian J Pharm Sci 76: 415-22, 2014.

13. Shetty D, Kim YJ, Shim H and Snyder JP: Eliminating the heart from the curcumin molecule: Monocarbonyl curcumin mimics (MACs). Molecules 20: 249-292, 2014.

14. Manju V and Nalini N: Chemopreventive efficacy of ginger, a naturally occurring anticarcinogen during the initiation, post-initiation stages of 1,2 dimethylhydrazine-induced colon cancer. Clin Chim Acta 358: 60-67, 2005.
15. Yang CL, Liu YY, Ma YG, Xue YX, Liu DG, Ren Y, Liu XB, $\mathrm{Li}$ Y and Li Z: Curcumin blocks small cell lung cancer cells migration, invasion, angiogenesis, cell cycle and neoplasia through Janus kinase-STAT3 signalling pathway. PLoS One 7: e37960, 2012

16. García-Niño WR, Tapia E, Zazueta C, Zatarain-Barrón ZL, Hernández-Pando R, Vega-García CC and Pedraza-Chaverrí J: Curcumin pretreatment prevents potassium dichromate-induced hepatotoxicity, oxidative stress, decreased respiratory complex I activity, and membrane permeability transition pore opening. Evid Based Complement Alternat Med 2013: 424692, 2013.

17. Jana S, Rudra DS, Paul S and Snehasikta S: Curcumin delays endometriosis development by inhibiting MMP-2 activity. Indian J Biochem Biophys 49: 342-348, 2012.

18. Jana S, Paul S and Warnakar SS: Curcumin as anti-endometriotic agent: Implication of MMP-3 and intrinsic apoptotic pathway. Biochem Pharmacol 83: 797-804, 2012.

19. Kang Y, Hu W, Bai E, Zheng H, Liu Z, Wu J, Jin R, Zhao C and Liang G: Curcumin sensitizes human gastric cancer cells to 5-fluorouracil through inhibition of the NFKB survival-signaling pathway. Onco Targets Ther 9: 7373-7384, 2016.

20. Tong W, Wang Q, Sun D and Suo J: Curcumin suppresses colon cancer cell invasion via AMPK-induced inhibition of NF- $\kappa \mathrm{B}$ uPA activator and MMP9. Oncol Lett 12: 4139-4146, 2016.

21. Gong G, Pan Q, Wang K, Wu R, Sun Y and Lu Y: Curcumin-incorporated albumin nanoparticles and its tumor image. Nanotechnology 26: 045603, 2015

22. Jiang GM, Xie WY, Wang HS, Du J, Wu BP, Xu W, Liu HF, Xiao P, Liu ZG, Li HY, et al: Curcumin combined with FAPac vaccine elicits effective antitumor response by targeting indolamine-2,3-dioxygenase and inhibiting EMT induced by TNF- $\alpha$ in melanoma. Oncotarget 6: 25932-25942, 2015.

23. Cao F, Liu T, Xu Y, Xu D and Feng S: Curcumin inhibits cell proliferation and promotes apoptosis in human osteoclastoma cell through MMP-9, NF- $\mathrm{KB}$ and JNK signaling pathways. Int J Clin Exp Pathol 8: 6037-6045, 2015.

24. Li ZC, Zhang LM, Wang HB, Ma JX and Sun JZ: Curcumin inhibits lung cancer progression and metastasis through induction of FOXO1. Tumor Biol 35: 111-116, 2014.

25. Wang Q, Qu C, Xie F, Chen L, Liu L, Liang X, Wu X, Wang P and Meng Z: Curcumin suppresses epithelial-to-mesenchymal transition and metastasis of pancreatic cancer cells by inhibiting cancer-associated fibroblasts. Am J Cancer Res 7: 125-133, 2017.

26. Leu TH, Su SL, Chuang YC and Maa MC: Direct inhibitory effect of curcumin on Src and focal adhesion kinase activity. Biochem Pharmacol 66: 2323-2331, 2003. 